\title{
Elevated Linoleic Acid (A Pro-Inflammatory PUFA) and Liver Injury in a Treatment Naive HIV-HCV Co-Infected Alcohol Dependent Patient
}

\author{
Vatsalya Vatsalya ${ }^{1,2^{*}}$, Shirish S. Barve ${ }^{1,3}$, Craig J. McClain ${ }^{1,3,4}$, Vijay A. Ramchandani2 \\ ${ }^{1}$ Division of Gastroenterology, Hepatology and Nutrition, Department of Medicine, University of \\ Louisville School of Medicine, Louisville, USA \\ ${ }^{2}$ Section on Human Psychopharmacology, LCTS/DICBR/NIAAA at National Institutes of Health, Bethesda, USA \\ ${ }^{3}$ Department of Pharmacology and Toxicology, University of Louisville School of Medicine, Louisville, USA \\ ${ }^{4}$ Robley Rex VA Medical Center, Louisville, USA \\ Email: *v0vats01@exchange.louisville.edu
}

Received 14 April 2016; accepted 1 July 2016; published 4 July 2016

Copyright (C) 2016 by authors and Scientific Research Publishing Inc.

This work is licensed under the Creative Commons Attribution International License (CC BY).

http://creativecommons.org/licenses/by/4.0/

c) (7) Open Access

\begin{abstract}
HIV and HCV co-infection is a unique disease condition, and medical management of such condition is difficult due to severity and systemic complications. Added with heavy alcohol drinking, risk of liver injury increases due to several pro-inflammatory responses that subsequently get involved with alcohol metabolism. Elevated levels of fatty acids have been reported both in viral infections as well as alcoholic liver disease though such investigations have not addressed the adverse event with dual viral infection of HIV and HCV along with heavy drinking. This case report of a patient with excessive alcohol drinking and first time diagnosis of HIV and HCV dual infection, elaborating concurrent alteration in Linoleic Acid (LA) levels and pro-inflammatory shift in $\omega-6 / \omega-3$ ratio along with the elevations in liver injury markers. Elevated LA has been recently studied extensively for its role in alcoholic liver disease; and in the present case, we also found it to be clinically relevant to liver injury.
\end{abstract}

\section{Keywords}

Alcohol, Fatty Acids, HCV, HIV, Liver Injury

\footnotetext{
${ }^{*}$ Corresponding author.
}

How to cite this paper: Vatsalya, V., Barve, S.S., McClain, C.J. and Ramchandani, V.A. (2016) Elevated Linoleic Acid (A ProInflammatory PUFA) and Liver Injury in a Treatment Naive HIV-HCV Co-Infected Alcohol Dependent Patient. Journal of Biosciences and Medicines, 4, 23-27. http://dx.doi.org/10.4236/jbm.2016.47003 


\section{Introduction}

HCV infection is found in almost $50 \%$ of the HIV-infected individuals in the US (largely due to intravenous drug abuse), which may lead to faster progression to end-stage liver disease [1]. Viral infections have shown higher morbidity and mortality in patients who also drink heavily due to exacerbated immune dysregulation and clinical developments in liver both as a result of several pathological processes targeting liver condition as well as due to the adverse effects of antiretroviral (ART) therapy [2]. Therefore, it is essential that providers working with such special patient population who also drink heavily, be able to fully characterize the onset of liver injury supported by the knowledge of risk factors during the course of the disease for appropriating medical management. Several risk factors have been identified previously in this co-infected population, for example, HCV viral load, Ferritin levels, Body Mass Index [3] though more studies are needed to determine the markers with sensitivity to characterize early indication of liver injury when such patients report about heavy drinking history. Arrangements of fatty acids (FAs) participating in inflammation during liver injury due to heavy drinking [4] has been found as viable indicator of liver injury, and changes in the arrangement of the FAs could be an useful marker of liver injury in such complex comorbidity. A treatment naive HIV diagnosis in an alcohol dependent patient who was also confirmed with HCV infection is presented to discuss the changes in fatty acid panel and liver injury.

\section{Case Presentation}

The patient was a 41-year-old widowed male at the time of screening who started drinking at age eight and progressed to become a regular drinker by age 16. At screening, he reported heavy drinking for the last ten years and had a positive family history of alcoholism. He reported excessive drinking (one-two pints of hard liquor daily, [8.5 - 17 drinks]) after a major life event occurred as the death of his spouse (approximately eight months prior to admission). His BMI was 22; he reported heavy smoking (one pack daily), and recent involvement in unsafe lifestyle practice. He showed confirmatory signs of alcohol use disorder with withdrawal symptoms during the psychiatric evaluation. Patient also reported that he was never tested positive for viral infection or taken medication for it's treatment during intake. This patient was diagnosed with positive HCV and HIV viral tests during the screening. HCV RNA IU quantification was at 8,920,000 with genotype 1A. HIV infection was detected based on both the criteria for confirmation for HIV infection as developed by the Center for Disease Control; withHIV-1 Ab detection, and western blot assay at viral load of $>50$. His SCD4 count was 210, which put him in the category 2 according to the CD4+ T-Lymphocytic classification. The test was reconfirmed with western blot band with second positive test at bands p24, gp41, and gp120/160. There was no other remarkable systemic observation and he was not diagnosed with any other relevant medical condition, other than the discussed drug abuse and viral infection. This patient presented asymptomatic conditions of HIV infection (resembling criteria for "clinical category A").

This patient presented with a remarkable liver injury profile (Figure 1), with all the liver injury markers

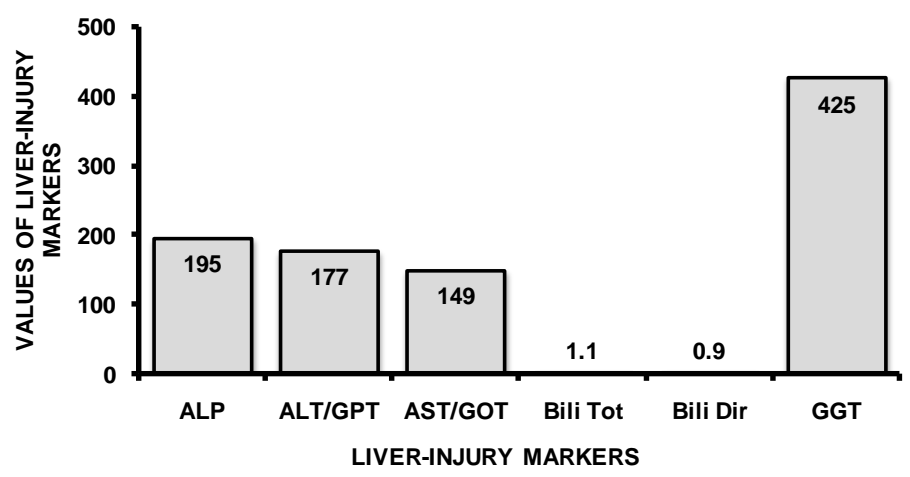

Figure 1. Elevation in Liver-injury in heavy drinking patient diagnosed with HIV and HCV co-infection. ALP: Alkaline Phosphatase (normal range: 37 - $116 \mathrm{U} / \mathrm{L}$ ); ALT/GPT: Alanine Transaminase (normal range: 6 - 41 U/L); AST/GOT: Aspartate Transaminase (normal range: 9 - 34 $\mathrm{U} / \mathrm{L}$ ); Bili Tot: Bilirubin, Total (normal range: 0.1 - $1.0 \mathrm{mg} / \mathrm{dL}$ ); Bili Dir: Bilirubin Direct (normal range: 0.0 - $0.2 \mathrm{mg} / \mathrm{dL}$ ); GGT: Gamma Glutamyltransaminase (normal range: 5 - $85 \mathrm{U} / \mathrm{L}$ ). 
showing above the normal values. In co-infected HIV+HCV cases, even with severe liver fibrosis and cirrhosis, $10 \%$ to $25 \%$ patients have shown normal alanine aminotransferase (ALT) levels [5]. Therefore, this case seems to show added severity in liver injury due to heavy alcohol drinking. Also, clinically relevant complete blood count (with differential) was identified at low hemoglobin (13.3, normal: $13.7-17.5 \mathrm{~g} / \mathrm{dL}$ ), hematocrit (37.2, normal: 40.1\% - 51.0\%) and MCV (78.6, normal: 79.0 - 92.2 fL) levels showing suppression of blood cell production this state of the infection. Ferritin was identified as high, 408 (26 - 388) as is generally observed in infections. Abnormal levels of leucocytes (WBC: 146/mcl; normal 0 - 25) were present and specific subtypes namely monocytes and lymphocytes [6] as shown in Table 1 . In this patient, fatty acid panel tested with blood (plasma) specimen showed that linoleic acid was the only PUFA that was abnormally high at $3957 \mathrm{nmol} / \mathrm{mL}$ (normal range: 2270 - 3850) that has shown having important role in liver injury [7]. Both HCV and HIV cause dysregulation of lipid metabolism, especially in polyunsaturated fatty acids (PUFAs) [8]. We also evaluated the $\omega-6 / \omega$-3 ratio, which was 18 (Total $\omega$-3 was 0.3 ; and Total $\omega$-6 was 5.4 , units $\mathrm{mmol} / \mathrm{L}$ ) in this patient supporting significant increase in the pro-inflammatory shift [9]. Triene Tetraene ratio was at the lower margin at 0.01 (normal range: 0.010 - 0.038). No other clinically significant change was observed in the FAs involved in inflammation; or in the lipid panel. Immunoglobin panel at this point was not abnormal as well. Patient received adequate medical management for alcohol withdrawal during the screening process [10] and was referred for infectious disease specialty.

\section{Discussion}

LA was significantly high in this patient and this case showed the relevance of analyzing the fatty acid panel with respect to liver injury. A pro-inflammatory response might be a useful measure to evaluate liver injury in patients who drink heavily and are diagnosed with viral co-infection. Early detection of viral infection could result in better medical management of the disease however few studies have evaluated alcohol drinking and their involvement in inflammation in such specific patient population. Involvement of elevated LA and subsequent changes in the fatty acids have been reported along with the pro-inflammatory and anti-inflammatory responses [11]. Understanding of pro-inflammatory response with the changes in $\omega-6$ FAs could further elucidate the state and potential progression of liver injury in such cases. A similar study reported that lifetime drinking and Hepatitis $\mathrm{C}$ virus infection play role in the progression of liver disease [12], however it did not discuss about the fatty acids and their involvement in inflammation and liver injury. More studies on specific fatty acids [13] for their role in inflammation; and their use as dietary supplements and metabolic responses are needed to investigate regulation and reduction of inflammation causing liver injury in this unique morbidity. This becomes much more relevant since ART therapy for HIV infection is known to cause liver injury, and our case report adds value to effective management of liver disease and treatment outcomes in HIV and HCV confected AD patients by having pre-treatment evaluation of pro-inflammatory response that might be adversely influencing the liver condition.

Table 1. Measures from differential CBC for White Blood Cell shows some significant elevation in macrophages (Lymphocytes and Monocytes) and Neutrophils (Polys) showing neutropenia. Normal ranges and measure units are based on the guidelines provided by National Institutes of Health and Mayo Clinic.

\begin{tabular}{cccc}
\hline CBC Differential & Values & Normal Ranges & Units \\
\hline Lymphocytes & $56.8 \uparrow$ & $21.8-53.1$ & $\%$ \\
Monocytes & $14.6 \uparrow$ & $5.3-12.2$ & $\%$ \\
Eosinophils & 4.6 & $0.8-7.0$ & $\%$ \\
Basophils & 0.9 & $0.2-1.2$ & $\%$ \\
Polys Absolute & $1.06 \downarrow$ & $1.78-5.38$ & K/uL \\
Lymphocytes Absolute & 2.6 & $1.32-3.57$ & K/uL \\
Monocytes Absolute & 0.67 & $0.30-0.82$ & K/uL \\
Eosinophils Absolute & 0.21 & $0.04-0.54$ & K/uL \\
Basophils Absolute & 0.04 & $0.01-0.08$ & K/uL \\
\hline
\end{tabular}




\section{Conclusion}

Liver injury is a known harmful outcome of heavy drinking and manifestation in HCV infection. Clinically relevant level of linoleic acid seems to correspond with the severity in liver injury in this dual viral infection that is likely getting negatively impacted by heavy alcohol intake as well, supporting involvement of ongoing proinflammatory response. Additional testing for comprehensive fatty acid panel could elucidate the ongoing changes in inflammatory response. In our patient, this was primarily influenced by increase in the $\omega-6$ fatty acid, and was noted by the elevation in linoleic acid level. Patients with HIV and HCV co-infection and excessive alcohol intake might need additional evaluation for liver state, before the start of ART treatment. Linoleic acid might serve as a marker of pro-inflammatory response along with the $\omega-6 / \omega-3$ ratio that likely could explain the severity in liver injury. Medical management of such cases becomes more challenging due to a pro-inflammatory response adversely effecting liver and limiting choices of antiretroviral therapy specific to HIV that also causes liver injury.

\section{Acknowledgements}

Study was supported by NIH-OD-OHSRP-12176 (VV), and Z99-AA999999 (VV); P50AA024337-01 (CJM) and ZIA-AA000466 (VAR). Authors thank Ms. Marion McClain for the editorial support.

\section{Author Contribution}

VV evaluated the patient data and interpreted the outcomes. VAR, SSB and CJM contributed scientifically. All the authors have approved the submission version of this manuscript.

\section{References}

[1] Center of Disease Control (2014) Viral Hepatitis Populations: HIV/AIDS and Viral Hepatitis. http://www.cdc.gov/hepatitis/Populations/hiv.htm

[2] Barve, S., Kapoor, R., Moghe, A., et al. (2009) Focus on the Liver: Alcohol Use, Highly Active Antiretroviral Therapy, and Liver Disease in HIV-Infected Patients. Alc Res \& Health: The Journal of the National Institute on Alcohol Abuse and Alcoholism, 33, 229-236.

[3] Bani-Sadr, F., Carrat, F., Bedossa, P., et al. (2006) Hepatic Steatosis in HIV-HCV Coinfected Patients: Analysis of Risk Factors. Aids, 20, 525-531. http://dx.doi.org/10.1097/01.aids.0000210606.63138.f5

[4] El-Zayadi, A.R. (2008) Hepatic Steatosis: A Benign Disease or a Silent Killer. World Journal of Gastroenterology, 14, 4120. http://dx.doi.org/10.3748/wjg.14.4120

[5] Martin-Carbonero, L., Ledinghen, V., Moreno, A., et al. (2009) Liver Fibrosis in Patients with Chronic Hepatitis C and Persistently Normal Liver Enzymes: Influence of HIV Infection. Journal of Viral Hepatitis, 16, 790-795. http://dx.doi.org/10.1111/j.1365-2893.2009.01133.x

[6] McClain, C.J., Hill, D.B., Song, Z., Deaciuc, I. and Barve, S. (2002) Monocyte Activation in Alcoholic Liver Disease. Alcohol, 27, 53-61. http://dx.doi.org/10.1016/S0741-8329(02)00212-4

[7] Nanji, A.A. and French, S.W. (1989) Dietary Linoleic Acid Is Required for Development of Experimentally Induced Alcoholic Liver Injury. Life Sciences, 44, 223-227. http://dx.doi.org/10.1016/0024-3205(89)90599-7

[8] Miyoshi, H., Moriya, K. and Tsutsumi, T. (2011) Pathogenesis of Lipid Metabolism Disorder in Hepatitis C: Polyunsaturated Fatty Acids Counteract Lipid Alterations Induced by the Core Protein. Journal of Hepatology, 54, 432-438. http://dx.doi.org/10.1016/j.jhep.2010.07.039

[9] Simopoulos, A.P. (2002) The Importance of the Ratio of Omega-6/Omega-3 Essential Fatty Acids. Biomedicine \& Pharmacotherapy, 56, 365-379. http://dx.doi.org/10.1016/S0753-3322(02)00253-6

[10] Pettinati, H.M., Weiss, R.D., Miller, W.R., Donovan, D., Ernst, D.B., Rounsaville, B.J., Series, C.M. and Mattson, M.E. (2004) Medical Management Treatment Manual. A Clinical Research Guide for Medically Trained Clinicians Providing Pharmacotherapy as Part of the Treatment for Alcohol Dependence. COMBINE Monograph Series, 2.

[11] Simopoulos, A.P. (2008) The Omega-6/Omega-3 Fatty Acid Ratio, Genetic Variation, and Cardiovascular Disease. Asia Pacific Journal of Clinical Nutrition, 17, 131-134.

[12] Ostapowicz, G., Watson, K.J., Locarnini, S.A. and Desmond, P.V. (1998) Role of Alcohol in the Progression of Liver Disease Caused by Hepatitis C Virus Infection. Hepatology, 27, 1730-1735. http://dx.doi.org/10.1002/hep.510270637

[13] Johnson, S.B., Gordon, E., McClain, C., Low, G.R. and Holman, R.T. (1985) Abnormal Polyunsaturated Fatty Acid Patterns of Serum Lipids in Alcoholism and Cirrhosis: Arachidonic Acid Deficiency in Cirrhosis. Proceedings of the National Academy of Sciences, 82, 1815-1818. http://dx.doi.org/10.1073/pnas.82.6.1815 


\section{Abbreviations}

AD: Alcohol Dependents;

ALT: Alanine aminotransferases;

CS: Clinically significant;

FA: Fatty Acid/s;

HIV: Human Immunodeficiency virus;

LA: Linoleic Acid;

NCS: Clinically non-significant;

PUFAs: Polyunsaturated fatty acids;

LDH: Lifetime drinking history.

Submit or recommend next manuscript to SCIRP and we will provide best service for you:

Accepting pre-submission inquiries through Email, Facebook, Linkedin, Twitter, etc A wide selection of journals (inclusive of 9 subjects, more than 200 journals)

Providing a 24-hour high-quality service

User-friendly online submission system

Fair and swift peer-review system

Efficient typesetting and proofreading procedure

Display of the result of downloads and visits, as well as the number of cited articles

Maximum dissemination of your research work

Submit your manuscript at: http://papersubmission.scirp.org/ 